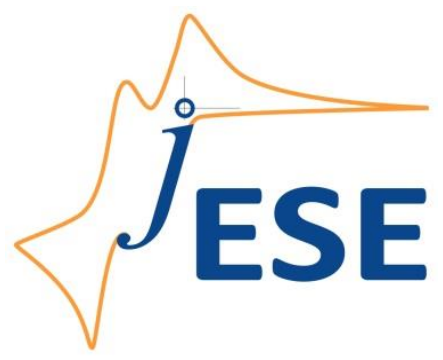

Open Access: ISSN 1847-9286

www.jESE-online.org

Original scientific paper

\title{
Voltammetric determination of hydroxylamine in water and waste water samples using a NiO nanoparticle/new catechol derivative modified carbon paste electrode
}

Mahbobeh Moazampour, Fahimeh Tahernejad-Javazmi, Maryam Salimi-Amiri*, Hassan Karimi-Maleh ${ }^{\bowtie}$ and Mehdi Hatami**

Department of Chemistry, Graduate University of Advanced Technology, Kerman, Iran

*Department of Physics, Sari Branch, Islamic Azad University, Sari, Iran

**Polymer Research Laboratory, University of Bonab, Bonab, Iran

${ }^{\otimes}$ Corresponding author: E-mail: h.karimi.maleh@gmail.com Tel.: +989112540112

Received: February 21, 2014; Revised: March 22, 2014; Published: December 6, 2014

\begin{abstract}
A (9,10-dihydro-9,10-ethanoanthracene-11,12-dicarboximido)-4-ethylbenzene-1,2-diol (DED) modified NiO/NPs carbon paste electrode "(DED/NiO nanoparticle (NiO/NPs)/CPE) was constructed for determination of hydroxylamine (HX). The cyclic voltammogram showed that the electrocatalytic oxidation of $H X$ at the surface of DED/NiO/NPS/CPE occurs at a potential of about 800 $m V$ less positive than with an unmodified electrode. Square-wave voltammetry results presented that the electrocatalytic oxidation peak currents of $\mathrm{HX}$ in $\mathrm{pH} 8.0$ had two linear dynamic ranges in the range of 0.1 to 2.0 and 2.0 to $400.0 \mu \mathrm{M} \mathrm{HX}$, with a detection limit of $0.07 \mu \mathrm{M}$. The kinetic parameters such as electron transfer coefficient $\alpha(0.47)$ and rate constant $\left(2.454 \times 10^{3} \mathrm{M}^{-1} \mathrm{~s}^{-1}\right)$ were determined for the chemical reaction between HX and DED. Finally, this method was evaluated for the determination of HX in water and waste water samples.
\end{abstract}

\section{Keywords}

Hydroxylamine; NiO nanoparticle; water and waste water analysis; sensor; voltammetry

\section{Introduction}

Hydroxylamine $(\mathrm{HX})$ is known as a type of reducing agent and is widely used in industrial and pharmaceutical applications. It has been identified as a key intermediate in nitrogen cycles and nitrous oxide production [1]. The quantitative determination of $H X$ is very important in both studies of biological processes and for industrial purposes. It has been confirmed that $H X$ is produced during the reduction of nitrates by Escherichia coli and Torula yeast [2]. 
Electrochemical analysis is gaining significance within industrial process control, environmental monitoring and various pharmaceutical and biotechnology applications [3-7]. The use of unmodified electrodes for electrochemical detection has a number of limitations, such as low selectivity and sensitivity, poor reproducibility, slow electron transfer reaction, low stability over a wide range of solution compositions and the high overpotential at which the electron transfer process occurs [8-10]. Chemical modification of inert substrate electrodes with redox active thin films offers significant advantages in the design and development of electrochemical sensors. In operation, the redox active sites shuttle electrons between the analyte and the electrodes with a significant reduction in activation overpotential [11]. A further advantage of chemically modified electrodes is that they are less prone to surface fouling and oxide formation, compared to inert substrate electrodes [12-14]. A wide variety of compounds have been used as electron transfer mediators for the modification of electrode surfaces in various procedures [15-17].

Nanotechnology has become one of the most interesting disciplines in science and technology today. The intense interest in nanotechnology is being driven by various interesting fields and is creating a new industrial revolution [18]. Nano-materials such as nanoparticles, carbon nanotubes or nanocomposite connected with biomolecules are being used for several bioanalytical applications [19-21]. Electroanalysis is taking advantage of all the possibilities offered by nanomaterials that are easy to detect using conventional electrochemical methods. Nanocomposite of a variety of shapes, sizes and compositions continues to change the field of bioanalytical measurement.

In the present work, we describe the preparation and suitability of a DED modified NiO/NPs carbon paste electrode as a new electrode for electrocatalysis and determination of $\mathrm{HX}$ in an aqueous buffer solution. To demonstrate the catalytic ability of the modified electrode toward the electrooxidation of $\mathrm{HX}$ in real samples, we examined the utility of this method for the voltammetric determination of $\mathrm{HX}$ in water and waste water samples.

\section{Experiment}

\section{Chemicals}

All chemicals used were of analytical reagent grade purchased from Merck (Darmstadt, Germany), unless otherwise stated. Doubly distilled water was used throughout.

$1.0 \times 10^{-2} \mathrm{~mol} \mathrm{~L}^{-1} \mathrm{HX}$ solution was prepared daily by dissolving $0.064 \mathrm{~g} \mathrm{HX}$ in water and the solution was diluted to $100 \mathrm{~mL}$ with water in a $100 \mathrm{~mL}$ volumetric flask. The solution was kept in a refrigerator at $4^{\circ} \mathrm{C}$ and in the dark. Further dilution was made with water.

Phosphate buffer solutions (sodium dihydrogen phosphate and disodium monohydrogen phosphate, plus sodium hydroxide, $0.1 \mathrm{~mol} \mathrm{~L}^{-1}$ ) (PBS) with different $\mathrm{pH}$ values were used.

High viscosity paraffin $\left(d=0.88 \mathrm{~kg} \mathrm{~L}^{-1}\right)$ from Merck was used as the pasting liquid for the preparation of the carbon paste electrode. Spectrally pure graphite powder (particle size $<50 \mu \mathrm{m}$ ) from Merck was used as the substrate for the preparation of the carbon paste electrode as a working electrode.

\section{Apparatus}

Cyclic voltammetry (CV), chronoamperometry and square wave voltammetry (SWV) were performed using an analytical system, Autolab, with PGSTAT 302N (Eco Chemie, The Netherlands). The system was run on a PC using GPES software. A conventional three-electrode cell assembly consisting of a platinum wire as an auxiliary electrode and an $\mathrm{Ag} / \mathrm{AgCl}\left(\mathrm{KCl}_{\text {sat }}\right)$ electrode as a 
reference electrode was used. The working electrode was either an unmodified carbon paste electrode (CPE) or a DED/NiO/NPs/CPE. X-ray powder diffraction studies were carried out using a STOE diffractometer with $\mathrm{Cu}-\mathrm{K}_{\alpha}$ radiation $(I=1.54 \AA$ ) $)$.

Preparation of the modified electrode

To prepare the modified electrode, $150.0 \mathrm{mg}$ of NiO/NPs and $70.0 \mathrm{mg}$ of DED was hand mixed with $780.0 \mathrm{mg}$ of graphite powder using a mortar and pestle. Using a syringe, 15 drops of paraffin were added to the mixture and mixed well for 55 min until a uniformly wetted paste was obtained. The paste was then packed into a glass tube. By pushing a copper wire down the glass tube into the back of the mixture, electrical contact was created. When necessary, a new surface was obtained by pushing an excess of the paste out of the tube and polishing it on weighing paper. The unmodified carbon paste electrode (CPE) was prepared in the same way without NiO/NPs and DED to the mixture, to be used for comparison purposes.

\section{Preparation of real samples}

Water samples were stored in a refrigerator immediately after collection. Ten millilitres of the sample was centrifuged for $15 \mathrm{~min}$ at $1500 \mathrm{rpm}$. The supernatant was filtered using a $0.45 \mu \mathrm{m}$ filter and then diluted three times with the PBS pH 8.0. The solution was transferred into the voltammetric cell to be analysed without any further pre-treatment. The standard addition method was used for the determination of $\mathrm{HX}$ in real samples.

\section{Results and discussion}

NiO/NPs characterisation

$\mathrm{NiO} / \mathrm{NPs}$ were analysed by XRD analyses. The XRD pattern of NiO/NPs nanopowders in the $2 \theta$ range of $10-80^{\circ}$ is shown in Fig. 1.

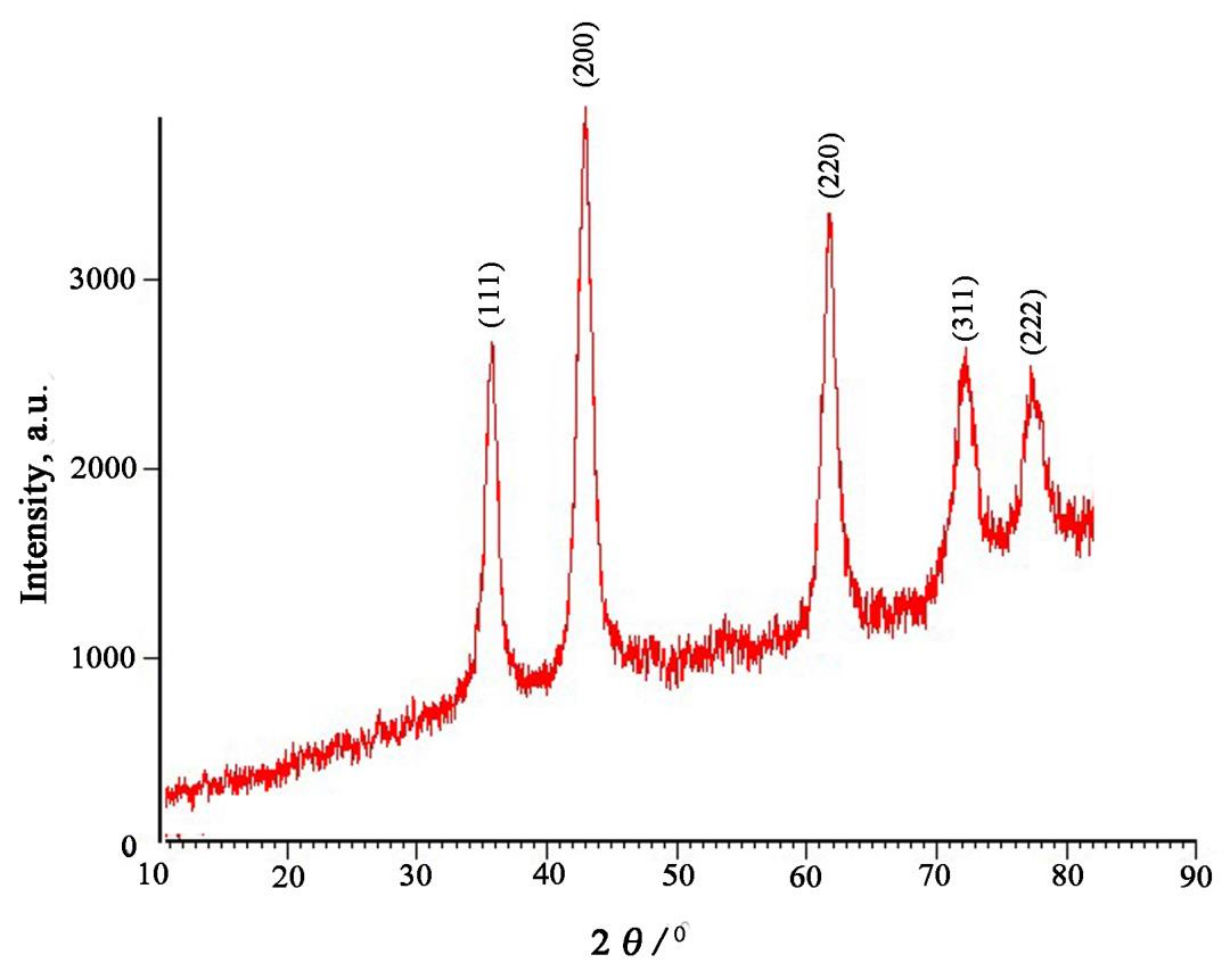

Figure 1. XRD patterns of as-synthesised NiO/NPs nanoparticles. 
Figure 1 clearly proves the presence of NiO/NPs. An average diameter of as-synthesised $\mathrm{NiO} / \mathrm{NPs}$ was calculated from the broadness peak $\left(2 \theta=44^{\circ}\right)$ by using the Scherrer equation $D=K \lambda / \beta \cos \theta$, and measured about $25.0 \mathrm{~nm}$.

\section{Electrochemical investigation}

Figure 2 depicts the cyclic voltammetry responses from the electrochemical oxidation of 400 $\mu \mathrm{M} \mathrm{HX}$ at DED/NiO/NPs/CPE (curve c), DED/CPE (curve b), NiO/NPs/CPE (curve d) and unmodified $\mathrm{CPE}$ (curve e). As shown, the anodic peak potential for HX oxidation at DED/NiO/NPs/CPE (curve c) and at DED/CPE (curve b) was about $200 \mathrm{mV}$, while at NiO/NPs/CPE (curve d); the peak potential was about $1000 \mathrm{mV}$. At the unmodified CPE, the peak potential of $\mathrm{HX}$ was about $1050 \mathrm{mV}$ (curve e). From these results, it was concluded that the best electrocatalytic effect for $\mathrm{HX}$ oxidation was observed at DED/NiO/NPs/CPE (curve c).

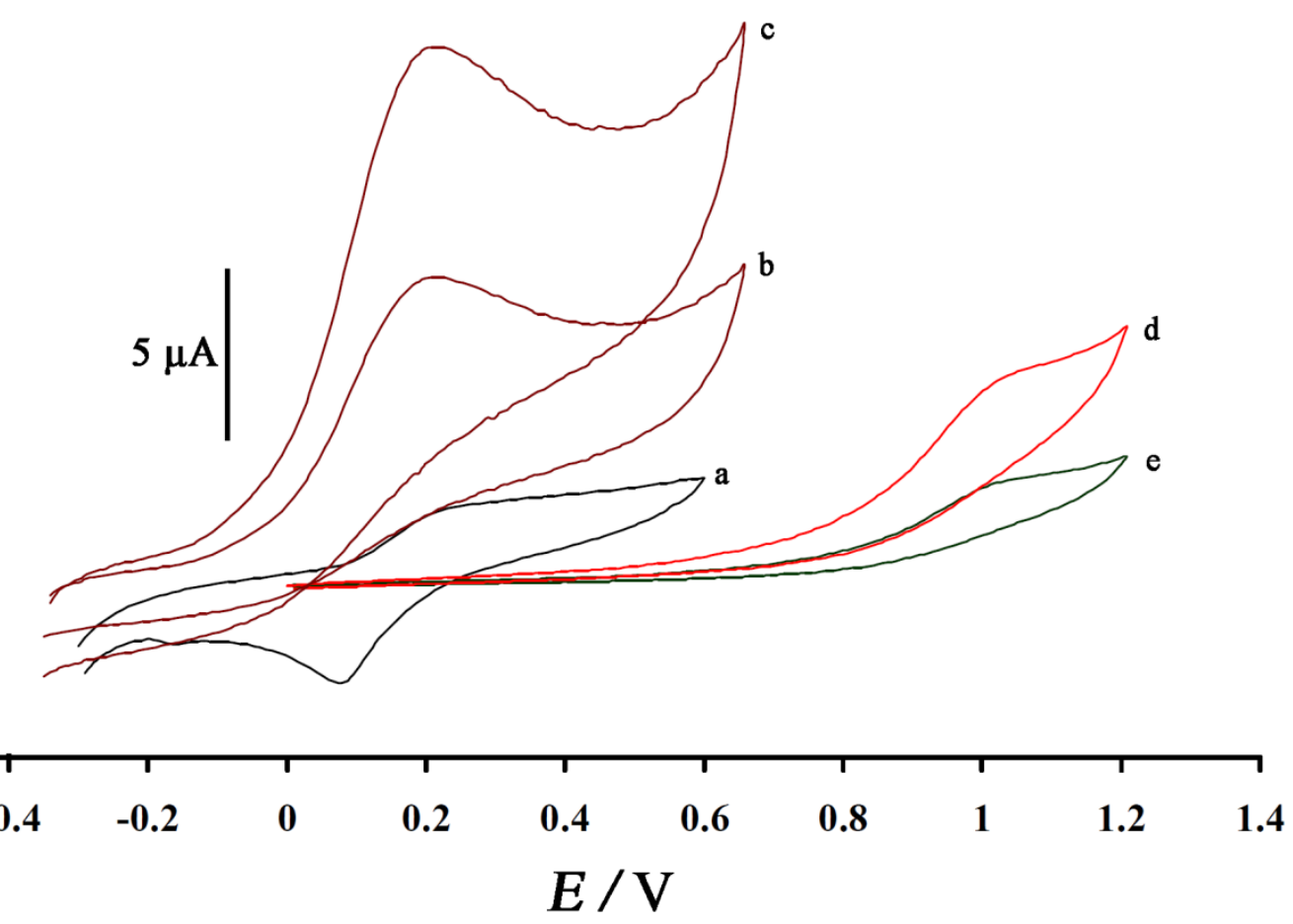

Figure 2. Cyclic voltammograms of (a) the buffer solution at DED/NiO/NPs/CPE; (b) $400 \mu M H X$ at DED/CPE; (c) $400 \mu \mathrm{M} H X$ at DED/NiO/NPs/CPE; (d) 400. $\mu \mathrm{M} \mathrm{HX}$ at NiO/NPs/CPE; (e) $400 \mu \mathrm{M}$ $H X$ at CPE. Conditions: $0.1 \mathrm{~mol} \mathrm{~L}^{-1} P B S(p H ~ 8.0)$, scan rate of $20 \mathrm{mV} \mathrm{s}^{-1}$.

For example, the results show that the peak potential of $\mathrm{HX}$ oxidation at DED/NiO/NPs/CPE (curve c) shifted by about 800 and $850 \mathrm{mV}$ toward less positive values when compared with $\mathrm{NiO} / \mathrm{NPs} / \mathrm{CPE}$ (curve d) and unmodified CPE (curve e), respectively. Additionally, DED/NiO/NPs/CPE showed higher anodic peak current for the oxidation of $\mathrm{HX}$ compared to DED/CPE, indicating that the combination of $\mathrm{NiO} / \mathrm{NPs}$ and the mediator significantly improved the performance of the electrode toward HX oxidation. In fact, DED/NiO/NPS/CPE in the absence of HX exhibited a wellbehaved redox reaction (Figure $2 \mathrm{a}$ ) in the buffer solution $(\mathrm{pH} 8.0)$. However, there was a drastic increase in the anodic peak current in the presence of $400 \mu \mathrm{M} \mathrm{HX}$ (curve c), which can be related to the electrocatalytic role of DED/NiO/NPs/CPE towards oxidation of HX.

We observed a linear variation of the peak current with the square root of scan rate $\left(v^{1 / 2}\right)$ at scan rates ranging from $2-12 \mathrm{mV} \mathrm{s}^{-1}$ at $\mathrm{pH} 8.0$ (Figure 3 ). This result clearly indicates a diffusioncontrolled electrooxidation process [22]. 


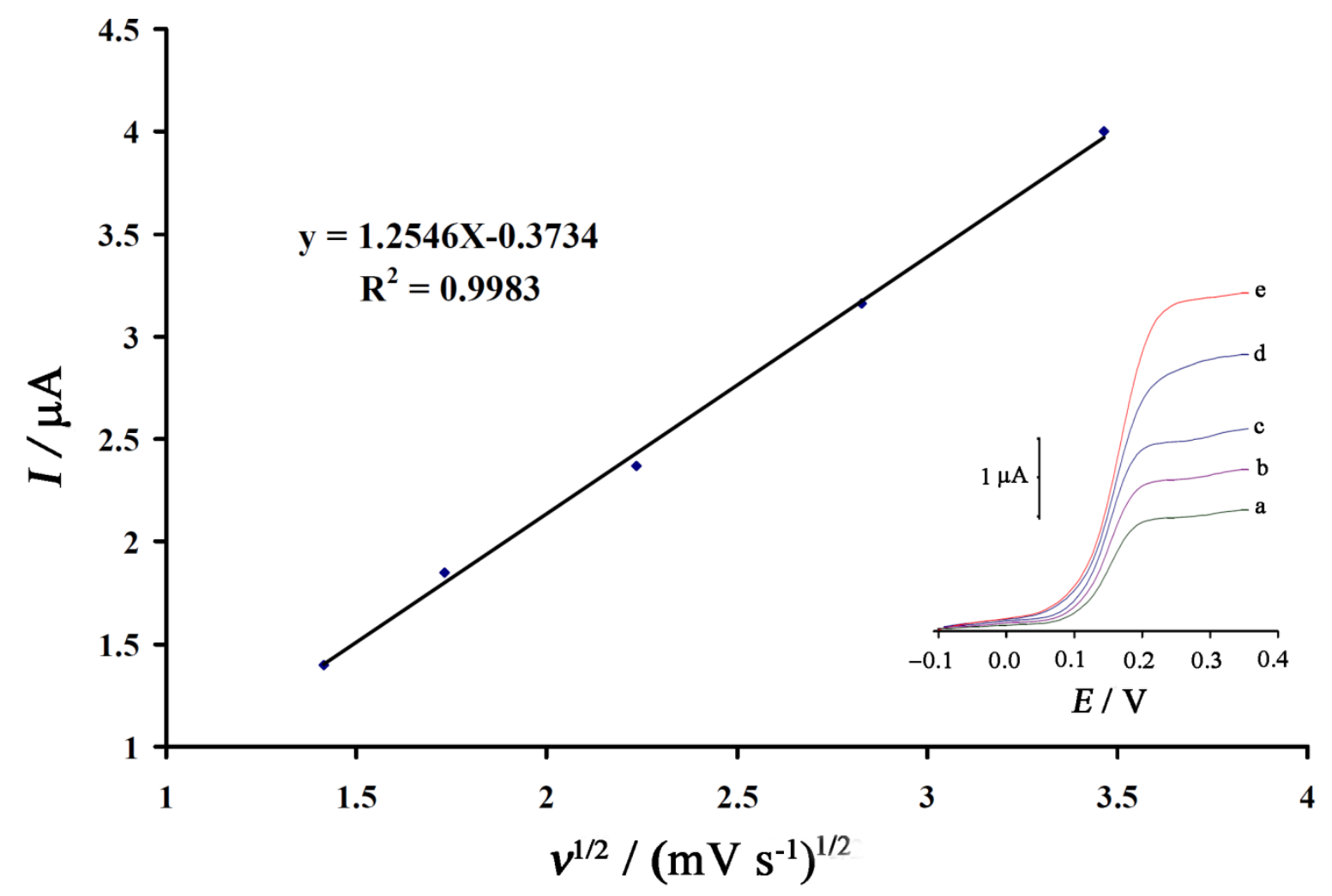

Figure 3 Plot of $\mathrm{I}_{p a}$ versus $\mathrm{v}^{1 / 2}$ for the oxidation of $100.0 \mu \mathrm{M} \mathrm{HX}$ at various scan rates of (a) 2.0; (b) 3.0; (c) 5.0; (d) 8.0; (e) $12.0 \mathrm{mV} \mathrm{s}^{-1}$ in $0.1 \mathrm{~mol} \mathrm{~L}^{-1}$ phosphate buffer solution (pH 8.0) at $\mathrm{NiO} / \mathrm{NPs} / D E D / C P E$. Inset: Cyclic voltammograms of $100.0 \mu \mathrm{M} \mathrm{HX}$ at various scans.

To obtain information about the rate-determining step, a Tafel plot was drawn, derived from points in the Tafel region of the linear sweep voltammogram (Figure 4). The slope of the Tafel plot was equal to $n(1-\alpha) F / 2.3 R T$, which resulted in $0.1115 \mathrm{~V}_{\text {decade }}{ }^{-1}$ [23]. Therefore, we obtained the value of $\alpha$ being equal to 0.47 .

For further investigations, the value of $\alpha$ was calculated for the oxidation of $\mathrm{HX}$ at $\mathrm{pH} 8.0$ for both the modified and unmodified paste electrodes using one other method (see equation 1):

$$
\alpha n_{\alpha}=0.048 /\left(E_{\mathrm{P}}-E_{\mathrm{P} / 2}\right)
$$

where $E_{\mathrm{P} / 2}$ is the potential corresponding to $I_{\mathrm{P} / 2}$. The values for $\alpha \mathrm{n}_{\alpha}$ were found to be 0.47 and 0.12 at the surface of DED/NiO/NPs/CPE and CPE, respectively. This result was also confirmed by the larger $I_{\mathrm{pa}}$ values recorded during linear seep voltammetry at DED/NiO/NPs/CPE.

Chronoamperometric measurements of $\mathrm{HX}$ at DED/NiO/NPS/CPE were carried out for various concentrations of $\mathrm{HX}$ in buffered aqueous solutions $(\mathrm{pH}$ 8.0) by setting the working electrode potentials at $0.0 \mathrm{mV}$ and $400 \mathrm{mV}$ vs. $\mathrm{Ag} / \mathrm{AgCl} / \mathrm{KCl}_{\text {sat }}$ (Figure $5 \mathrm{~A}$ ). For an electroactive material $(\mathrm{HX}$, in this case) with a diffusion coefficient of $D$, the current observed for the electrochemical reaction at the mass transport limited condition was described using the Cottrell equation. Experimental plots of I vs. $t^{-1 / 2}$ were employed, with the best fits for $300 \mu \mathrm{M}$ of $\mathrm{HX}$ (Figure $5 \mathrm{~B}$ ). The slope of the resulting straight line was then plotted against $\mathrm{HX}$ concentration (Figure $5 \mathrm{~B}$ ). From the resulting slope and Cottrell equation, the mean value of the $D$ was found to be $2.1 \times 10^{-6} \mathrm{~cm}^{2} \mathrm{~s}^{-1}$ [24]. 




Figure 4. Tafel plot for DED/NiO/NPS/CPE in $0.1 \mathrm{~mol} \mathrm{~L}^{-1} P B S(p H$ 8.0) with a scan rate of 8 in the presence of $100.0 \mu \mathrm{M} \mathrm{HX}$.
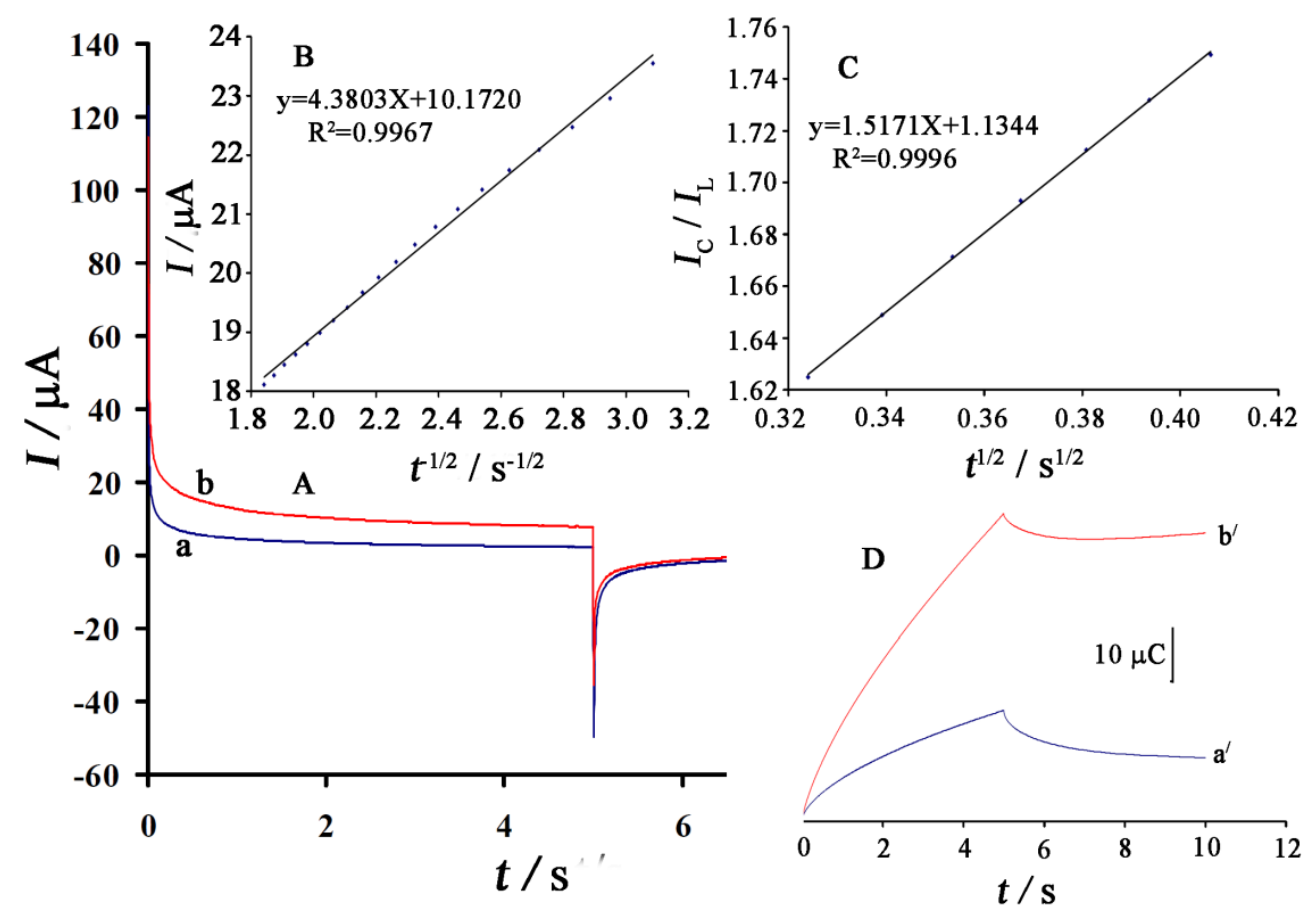

Figure 5. A - Chronoamperograms obtained at DED/NiO/NPS/CPE (a) in the absence and in the presence of (b) $300 \mu \mathrm{M} \mathrm{HX}$ at $\mathrm{pH}$ 8.0; $\mathbf{B}$-Cottrell's plot for the data from the chronoamperograms; $C$-Dependence of IC/IL on $t^{1 / 2}$ derived from the chronoamperogram data; $D$ - The charge-time curves $\left(a^{\prime}\right)$ for curve $(a)$ and $\left(b^{\prime}\right)$ for curve (b).

The rate constant for the chemical reaction between $\mathrm{HX}$ and redox sites in DED/NiO/NPs/CPE, $k_{\mathrm{h}}$, can be evaluated by chronoamperometry according to the method set out by Galus [25]:

$$
I_{C} / I_{L}=\pi^{1 / 2} \gamma^{1 / 2}=\pi^{1 / 2}\left(k C_{b} t\right)^{1 / 2}
$$

Where $I_{C}$ is the catalytic current of $\mathrm{HX}$ at DED/NiO/NPS/CPE, $I_{L}$ the limited current in the absence of $\mathrm{HX}$ and $t$ is the time elapsed (s). The above equation can be used to calculate the rate 
constant of the catalytic process $k_{\mathrm{h}}$. Based on the slope of the $I_{\mathrm{C}} / I_{\mathrm{L}}$ versus $t^{1 / 2}$ plots (Figure $5 \mathrm{C}$ ), $k_{\mathrm{h}}$ can be obtained for a given $\mathrm{HX}$ concentration. From the values of the slopes, an average value of $k_{\mathrm{h}}$ was found to be $k_{\mathrm{h}}=2.454 \times 10^{3} \mathrm{M}^{-1} \mathrm{~s}^{-1}$. The value of $k_{\mathrm{h}}$ also explains the sharp feature of the catalytic peak observed for catalytic oxidation of $\mathrm{HX}$ at the surface of DED/NiO/NPS/CPE.

Double potential step chronocoulometry, as well as other electrochemical methods, was in addition employed for the investigation of the electrode processes at DED/NiO/NPs/CPE. Forward and backward potential step chronocoulometry on the modified electrode in a blank buffer solution showed very symmetrical chronocoulograms. These had about an equal charge consumed for both oxidation and reduction of the $\mathrm{DED}_{\text {Red }} / \mathrm{DED}_{\mathrm{Ox}}$ redox system in DED/NiO/NPs/CPE. However, in the presence of $\mathrm{HX}$, the charge value associated with forward chronocoulometry was significantly greater than that observed for the backward chronocoulometry (Figure 5D). This behaviour is typical of that expected for electrocatalysis at a chemically modified electrode [26].

Stability and reproducibility

The repeatability and stability of modified electrode was investigated using CV measurements of $400.0 \mu \mathrm{M} \mathrm{HX}$ in a buffer solution. The relative standard deviation (RSD) for five successive assays was $1.4 \%$. When seven different DED/NiO/NPs/CPEs were used, the RSD for ten measurements was $2.1 \%$. When the electrode was stored in the laboratory, the modified electrode retained $95 \%$ of its initial response after a week and $92 \%$ after 30 days (see Figure 6). These results indicate that DED/NiO/NPs/CPE has good stability and reproducibility, and could be used for HX measurements.

\section{Determination of $H X$ individually}

Square wave voltammetry (SWV) was used to determine the concentration of HX. Since square wave voltammetry has a much higher current sensitivity and better resolution than cyclic voltammetry, the SWV was used for the determination of HX (Figure 7 inset). The plot of peak current vs. the $\mathrm{HX}$ concentration consisted of two linear segments with slopes of 5.9035 and $0.1498 \mu \mathrm{A} / \mu \mathrm{M}$ at the concentration ranges of 0.1-2.0 $\mu \mathrm{M}$ and 2.0-400.0 $\mu \mathrm{M}$, respectively (Fig. 7).

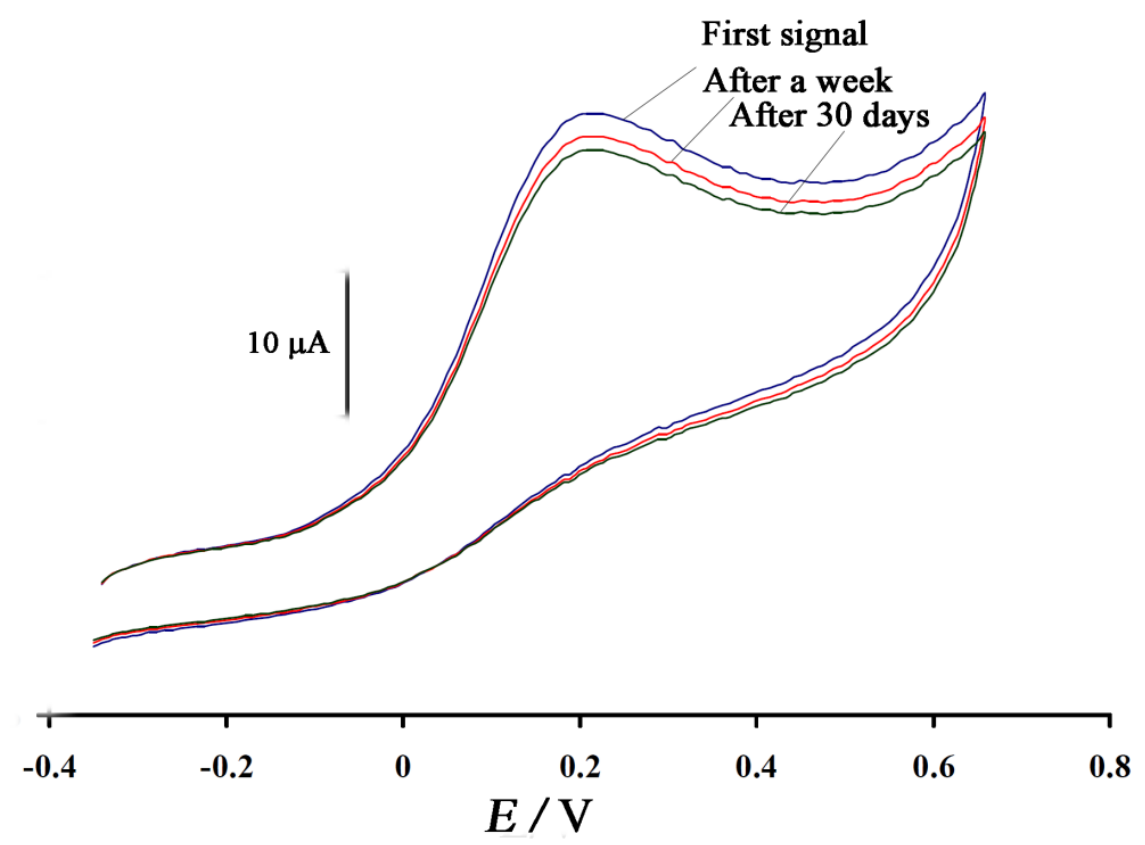

Figure 6. Cyclic voltammograms of $300 \mu \mathrm{MHX}$ at a surface of DED/NiO/NPs/CPE in a $0.1 \mathrm{~mol}$ $L^{-1}$ phosphate buffer solution ( $\mathrm{pH}$ 8.0) at different times. 
The decreasing of sensitivity (slope) of the second linear segment was likely due to kinetic limitation. The detection limit was determined as $0.07 \mu \mathrm{M}$ for $\mathrm{HX}$ based on $Y_{\mathrm{LOD}}=Y_{\mathrm{B}}+3 \sigma$.

\section{Interference study and real sample studies}

Analytical selectivity was one of the important parameters that affected the accuracy of the analysis. In order to evaluate the selectivity of the proposed method for the determination of HX, the influence of various substances as potentially interfering compounds, which can be present in the water and waste water samples with the determination of $\mathrm{HX}$, were studied under optimum conditions with $1.0 \mu \mathrm{M} \mathrm{HX}$ at $\mathrm{pH}$ 8.0. The tolerance limit was taken as the maximum concentration of the foreign substances, which caused an approximate $3 \%$ relative error (in potential or current) in the determination. The result of interfering studied for some of the various substances in oxidation current and oxidation peak potential of $\mathrm{HX}$ showed that 1000 -fold of $\mathrm{Ni}^{2+}, \mathrm{CN}^{-}, \mathrm{Ca}^{2+}$, $\mathrm{Mg}^{2+}, \mathrm{Mn}^{+2}, \mathrm{~K}^{+}, \mathrm{Na}^{+}, \mathrm{Cl}^{-}$and $\mathrm{SCN}^{-}, 800$-fold of glucose, sucrose, lactose and fructose did not affect the selectivity.

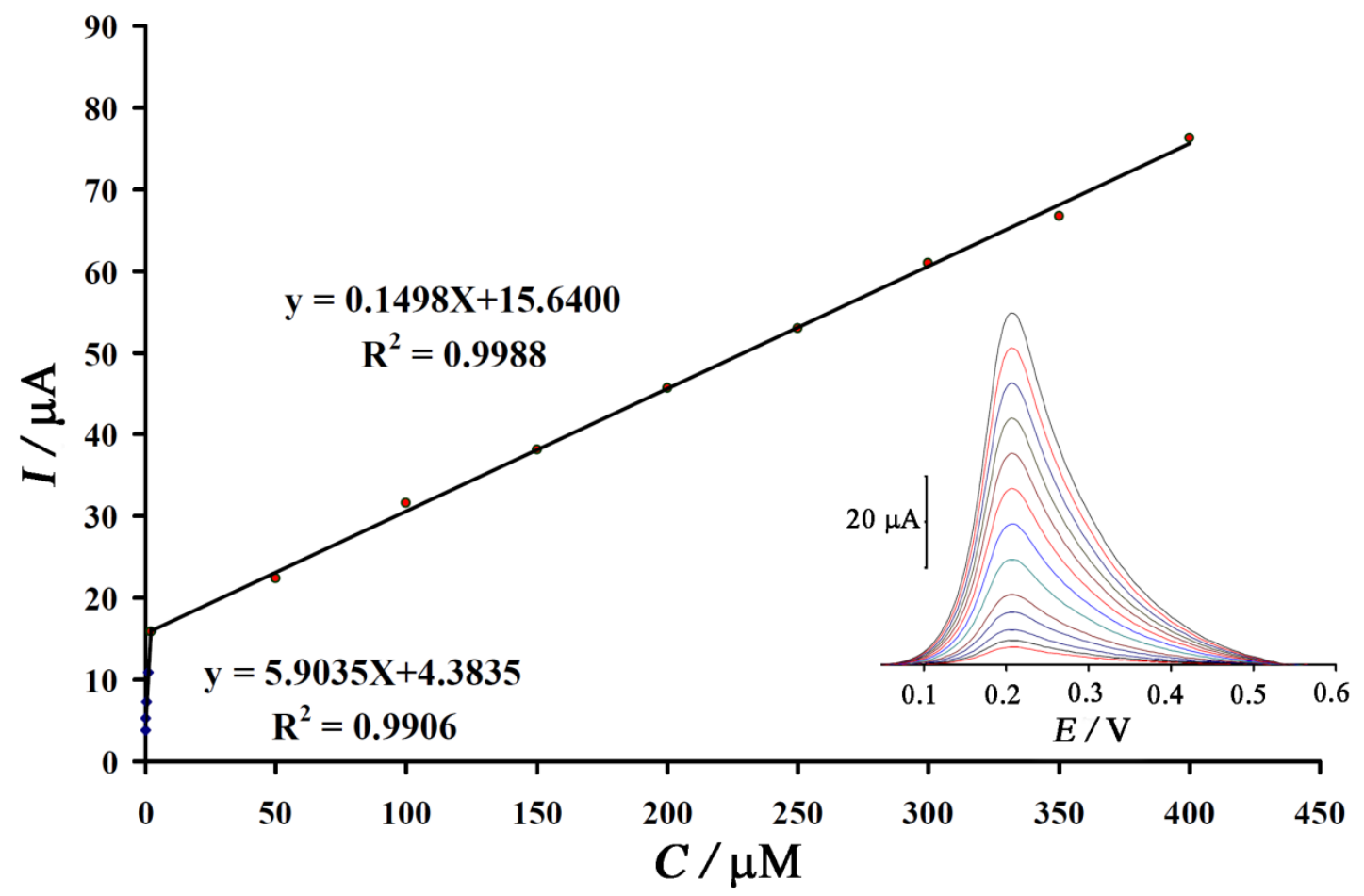

Figure 7. The plots of the electrocatalytic peak current as a function of $H X$ concentration. Inset shows the SWVs of DED/NiO/NPS/CPE in a $0.1 \mathrm{~mol} \mathrm{~L}^{-1}$ phosphate buffer solution ( $\mathrm{pH}$ 8.0) containing different concentrations of HX. From bottom-up corresponds to 0.0, 0.1, 0.5, 1.0, 2.0, 50.0, 100.0, 150.0, 200.0, 250.0,300.0,350.0 and 400.0 $\mu \mathrm{M}$ of $\mathrm{HX}$.

In order to demonstrate the applicability of the new sensor in determining $\mathrm{HX}$ in real samples, we used the new sensor in determining $\mathrm{HX}$ in tap water, river water, wastewater and well water. The determinations of $\mathrm{HX}$ in samples were carried out using the standard addition method (Table 1). The accuracy of the method was examined by comparing the results obtained from this method with published methods for the determination of $\mathrm{HX}$ [2]. The results from the statistical calculation indicated good agreement between them for the mean values ( $t$-test) and the precision (F-test) in the determination of $\mathrm{HX}$ in real samples for the three analyses. It was clear that a modified electrode was capable of voltammetric determination of $\mathrm{HX}$, with high selectivity and good reproducibility. 
Table 1: Determination of HX in water samples ( $n=3)$.

\begin{tabular}{lccccccc}
\hline Sample & Added, $\mu \mathrm{M}$ & Founded, $\mu \mathrm{M}$ & Published method, $\mu \mathrm{M}$ & $F_{\mathrm{ex}}$ & $F_{\text {tab }}$ & $t_{\mathrm{ex}}$ & $t_{\text {tab }}$ \\
\hline Tap water & 1.00 & $1.05 \pm 0.10$ & $0.98 \pm 0.11$ & 6.3 & 19.0 & 1.2 & 3.8 \\
Well water & 5.0 & $4.85 \pm 0.16$ & $5.22 \pm 0.32$ & 7.8 & 19.0 & 1.5 & 3.8 \\
River water $^{\mathrm{a}}$ & 10.0 & $10.45 \pm 0.65$ & $10.55 \pm 0.76$ & 9.6 & 19.0 & 2.1 & 3.8 \\
Waste water & 30.0 & $29.73 \pm 0.75$ & $30.75 \pm 1.2$ & 13.5 & 19.0 & 3.2 & 3.8 \\
\hline
\end{tabular}

${ }^{a}$ Tejan River, Sari, Iran

$F_{\text {ex }}$ - calculated $F$ value; $F_{\text {tab }}$ - reported $F$ value from F-test table with $95 \%$ confidence level and $2 / 2$ degree of freedom; $t_{\mathrm{ex}}$ - calculated $t$; $t_{\mathrm{tab}}$ - reported $t$ value from student t-test table with $98 \%$ confidence level.

\section{Conclusion}

A carbon paste electrode modified with NiO/NPs and DED was used for electrocatalytic determination of $\mathrm{HX}$. The results showed that the oxidation of $\mathrm{HX}$ was catalysed at $\mathrm{pH} 8.0$, whereas the peak potential of hydrazine was shifted by $800 \mathrm{mV}$ to a less positive potential at the surface of DED/NiO/NPS/CPE. In addition, it was shown that $\mathrm{HX}$ can be determined using the square wave voltammetry technique. The detection limit $(3 \sigma)$ was 0.07 according to the SWV method. The kinetic parameters, such as electron transfer coefficient, $\alpha(0.47)$ and a rate constant for the chemical reaction between $\mathrm{HX}$ and redox sites in DED/NiO/NPs/CPE, $k_{\mathrm{h}}\left(2.454 \times 10^{3} \mathrm{M}^{-1} \mathrm{~s}^{-1}\right)$ were also determined using electrochemical approaches. Finally, the electrocatalytic oxidation of $\mathrm{HX}$ at the surface of this modified electrode can be employed as a new method for the voltammetric determination of $\mathrm{HX}$ in real samples such as tap water, river water, wastewater and well water.

Acknowledgements: The authors wish to thank Gradate University of Advanced Technology, for their support.

\section{References}

[1] M. Mazloum-Ardakani, H. Beitollahi, Z. Taleat, H. Naeimi, Analytical Methods, 2 (2010) 1764-1769.

[2] R. Sadeghi, H. Karimi-Maleh, M. A. Khalilzadeh, H. Beitollahi, Z. Ranjbarha, M. B. Pasha Zanousi, Environmental Science and Pollution Research 20 (2013) 6584-6593

[3] J. B. Raoof, R. Ojani, H. Karimi-Maleh, Electroanalysis 20 (2008) 1259-1262.

[4] E. Mirmomtaz, A. A. Ensafi, H. Karimi-Maleh, Electroanalysis 20 (2008) 1973-1979

[5] H. Beitollahi, H. Karimi-Maleh, H. Khabazzadeh, Analytical Chemistry 80 (2008) 9848-9851

[6] M. A. Khalilzadeh, F. Khaleghi, F. Gholami, H. Karimi-Maleh, Analytical Letters, 42 (2009) 584-599.

[7] H. Karimi-Maleh, A. A. Ensafi, H. R. Ensafi, Journal of the Brazilian Chemical Society 20 (2009) 880-887.

[8] H. Karimi-Maleh, A. A. Ensafi, A. R. Allafchian, Journal of Solid State Electrochemistry 14 (2010) 9-15.

[9] M. A. Khalilzadeh, H. Karimi-Maleh, A. Amiri, F. Gholami, R. Motaghed mazhabi, Chinese Chemical Letters 21 (2010) 1467-1470..

[10] A. A. Ensafi, E. Khoddami, B. Rezaei, H. Karimi-Maleh, Colloids and Surfaces B: Biointerfaces 81 (2010) 42-49.

[11] M. A. Khalilzadeh, H. Karimi-Maleh, Analytical Letters 43 (2010) 186-196.

[12] A. A. Ensafi, H. Karimi-Maleh, S. Mallakpour, M. Hatami, Sensors and Actuators B 155 (2011) 464--72. 
[13] A. A. Ensafi, H. Karimi-Maleh, S. Mallakpour, B. Rezaei, Colloids and Surfaces B 87 (2011) 480-488.

[14] A .A. Ensafi, H. Karimi-Maleh, M. Ghiaci, M. Arshadi, Journal of Material Chemistry 21 (2011) 15022-15030

[15] R. Moradi, S. A. Sebt, H. Karimi-Maleh, R. Sadeghi, F. Karimi, A. Bahari, H. Arabi, Physical Chemistry Chemistry Physics 15 (2013) 5888-5897.

[16] M. Keyvanfard, R. Shakeri, H. Karimi-Maleh, K. Alizad, Materials Science and Engineering C 33 (2013) 811-816

[17] M. Roodbari Shahmiri, A. Bahari, H. Karimi-Maleh, R. Hosseinzadeh, N. Mirnia, Sensors and Actuators B 177 (2013) 70-77.

[18] M. Elyasi, M. A. Khalilzadeh, H. Karimi-Maleh, Food Chemistry 141 (2013) 4311-4317.

[19] A. L. Sanati, H. Karimi-Maleh, A. Badiei, P. Biparva, A. A. Ensafi, Materials Science and Engineering C 35 (2014) 379-385.

[20] H. Karimi-Maleh, M. Moazampour, H. Ahmar, H. Beitollahi, A. A. Ensafi, Measurement 51 (2014) 91-99

[21] T. Tavana, M. A. Khalilzadeh, H. Karimi-Maleh, A. A. Ensafi, H. Beitollahi, D. Zareyee, Journal of Molecular Liquids 168 (2012) 69-74.

[22] H. Karimi-Maleh, M. Moazampour, H. Ahmar, H. Beitollahi, A.A. Ensafi, Measurement 51 (2014) 91-99.

[23] N. B. Salah, F. M. Mhalla, Journal of Electroanalytical Chemistry 485 (2000) 42-48.

[24] M. Mazloum Ardakani, M. A. Karimi, S. M. Mirdehghan, M. M. Zare, R. Mazidi, Sensors and Actuators B 132 (2008) 52-59.

[25] Z. Galus, Fundamentals of Electrochemical Analysis, Ellis Horwood, New York, 1976.

[26] M. Keyvanfard, S. Sami, H. Karimi-Maleh, K. Alizad, Journal of the Brazilian Chemical Society 24 (2013) 32-39.

(C) 2014 by the authors; licensee IAPC, Zagreb, Croatia. This article is an open-access article distributed under the terms and conditions of the Creative Commons Attribution license (http://creativecommons.org/licenses/by/4.0/) (cc) EY 